\title{
ALTERIDADE E CITABILIDADE - BENJAMIN E LEVINAS
}

Ricardo Timm de Souza'

SÍNTESE - O texto pretende evidenciar de como, para além de preconceitos advindos do distanciamento de modelos de pensamento ou escolas filosóficas, é não somente útil como muito necessário que se dê uma aproximação entre as motivações básicas dos autores, aproximação esta que pode vir a se constituir em um útil viés interpretativo de toda uma "era filosófica" e de suas exigências de inteligibilidade.

PALAVRAS-CHAVE - Alteridade. Benjamin. Levinas.

\begin{abstract}
This article seeks to show that, in order to go beyond the prejudices that stem from thinking models or philosophical schools, it is not only useful but also necessary that a rapprochement be undertaken between the basic motivations of authors, so as to constitute an interpretative framework for an entire "philosophical age" and its intelligibility requirements.
\end{abstract}

KEY WORDS - Alterity. Benjamin. Levinas.

\section{Introdução}

A premência de questões filosóficas fundamentais aproxima mundos e cosmovisões diversos, formas diversas de abordagem de um mesmo problema central, o qual é percebido como o tema fundamental de um determinado corte históricocivilizatónio, de uma determinada "Era". Esta aproximação não se dá, muitas vezes, de uma forma que poderíamos chamar "consciente", na medida em que lida com dimensões de uma tal amplitude cultural que pode passar facilmente despercebida. Porém isso em nada atenua sua pregnância, pois tal aproximação não é um capricho ou uma retórica, mas o nervo da possibilidade de autocompreensão e da postulação de uma proposta de sentido de realidade que ultrapasse o domicílio de um determinado modelo de discurso, abrangendo universos cada vez mais amplos de inteligibilidade e se empenhando na tradução e retradução constante do filosoficamente essencial em outras línguas filosóficas e culturais.

Ainda mais, tal aproximação aparece, muitas vezes, antes como estruturas mutuamente excludentes ou imiscíveis do que como o que realmente são: formas

Professor do Programa de Pós-Graduaçăo em Filosofia, Faculdade de Filosofia e Ciências Humanas - PUCRS. 
diversas de abordar uma mesma questão de origem, uma mesma temática fundamental, ou a procura convergente por uma mesma dimensão de sentido de realidade.

Em nenhuma época como o século XX tal se dá de forma tão aguda; e temos tentado evidenciar tal fato em outros textos ${ }^{1}$. Em verdade, para um leitor algo mais "imparcial", é impressionante a convergência de sentido de construções filosóficas provindas de inspirações absolutamente diferentes a uma primeira vista. E, com isso, interfaces de diálogo profícuo são muitas vezes excluidas a priori do campo das possibilidades que traduzem tensões intelectuais do mais alto nível.

Nosso objetivo nesse pequeno texto é apontar de forma clara aspectos convergentes essenciais das obras de dois autores tidos pela mentalidade filosófica "normal" como absolutamente "diferentes" entre si: Walter Benjamin e Emmanuel Levinas. As noções de referência, que ocuparão aqui a mera posição de indicativos para um esboço de abordagem, são "citabilidade" e "alteridade".

\section{Walter Benjamin e o (apesar de tudo) citável}

O tema da narração ou narratividade - especificamente da citabilidade do tornado citável, do passado que se materializa num singular compósito intelectualmaterial que simultaneamente presentifica e impulsiona ao futuro de forma como que "transfigurada" as estruturas violentadas do pequeno e da história e de seus restos - é, reconhecidamente, uma das questões centrais do pensamento benjaminiano. Esse ativista das "pequenas" causas nunca se perdeu em teleologias onipotentes, mas fez da percepção das instâncias "menores" e para ele decisivas do real a base de sua própria - e dificílima -lucidez. Na articulação de suas idéias centrais, nenhum conceito permanece estático ou deslumbrado consigo mesmo, mas, antes, recai continuamente, com modéstia, na realidade fecundante da qual se origina. É por isso que Walter Benjamin pode ser considerado um autor tão "difícil": não autoriza generalizações e mostra agudamente a violência que elas comportam".

Cf. SOUZA, Ricardo Timm de. O século XX e a desagregação da totalidade. In: - Totalidade \& desagregação - sobre as fronteiras do pensamento e suas alternativas. Porto Alegre: EDIPUCRS, 1996, p. 15-29. É de se ressaltar que, se tal circunstância é já, normalmente, de difícil compreensão, ainda mais dificil é essa compreensão num meio como o nosso, marcado por carências diversas, recepções parciais de autores e obras e preconceitos de toda ordem, que criam uma estrutura de parcialidade filosófica difícil de ser superada. Para nós, sinais iniciais de maturidade intelectual se dão, exatamente, na possibilidade anunciada de romper a ignorância e o medo, raízes de todo o preconceito, em direção à corajosa e sempre muito difícil "intersecção" de inteligibilidades. Essa talvez seja uma tarefa essencial da nova geração de acadêmicos; com certeza é uma das mais urgentes.

2 É auspicioso e evidencia ao nosso ver maturidade intelectual o fato de que um tal pensamento essencialmente não rotulável ou classificável a priori se tome mais e mais alvo de interesse e estudo de uma nova geração de acadêmicos brilhantes' em nosso meio; a recepção de Walter Benjamin cresce, no Brasil, tanto em termos de quantidade como de qualidade. 
No presente contexto, analisaremos brevemente apenas um curto trabalho de Benjamin, mas um escrito fundamental: a famosa terceira "Tese" de "Sobre o conceito da história". 3

Sabemos que a coletânea das Teses e seus apêndices são aceitas como a última obra de Benjamin, e representam, inobstante sua concisão, uma síntese grandiosa de seu pensamento mais maduro e uma intervenção magistral no mundo das idéias do século XX, exorbitando infinitamente os meros chavões de "marxismo" ou "teologia", para citar apenas os mais comuns. Ao longo de dezoito teses curtas e dois apêndices, desdobra-se simultaneamente um agudo inventário do passado e toda uma profissão de fé na possibilidade de se pensar e construir um futuro humano - e isso por "debaixo" e apesar de um jargão aparentemente unívoco. Aqui, a tensão intelectual é máxima, sem, com isso, fechar-se numa estrutura auto-suficiente de referência.

\section{Vejamos o conteúdo da terceira Tese:}

"O cronista que narra os acontecimentos, sem distinguir entre os grandes e os pequenos, leva em conta que nada do que um dia aconteceu pode ser considerado perdido para a história. Sem dúvida, somente a humanidade redimida poderá apropriar-se totalmente de seu passado. Isso quer dizer: somente para a humanidade redimida o passado é citável, em cada um de seus momentos. Cada momento vivido transforma-se numa citation à l'ordre du jour - e esse dia é justamente o do juizo final."

O que temos, à primeira vista? Talvez tudo, menos o que um leitor desavisado costuma apreender a uma primeira leitura. Pois não se trata de algum discurso edificante ou "irrealista" (como poderia ser o passado citável em sua integralidade "sincrônica"?), mas da indicação de toda uma especial estrutura de compreensão da realidade, de um prisma desde o qual o real se mostra como tal, não a partir do estabelecimento de conceitos que o "expliquem", mas desde um fundamento de sentio que o justifique, e que justifique inclusive os conceitos daí deriváveis conceitos novos e que façam justiça à facticidade e temporalidade que habita cada ato humano ao longo da história. ${ }^{4}$

Nessa simples Tese, tempo e espaço assumem sentidos completamente diferentes daqueles comuns à tradição da filosofia: não são categorias "objetivas" ou "subjetivas" de interpretação da realidade, mas dimensões desde as quais a realidade pode assumir um sentido humano de futuro. O passado tem de ser julgado; a

\footnotetext{
BENJAMIN, Walter. "Über den Begriff der Geschichte". Utilizaremos a versão traduzida por Sérgio P. Rouanet, in: BENJAMIN, W. Obras Escolhidas - magia e técnica, arte e politica - ensaios sobre literatura e história da cultura. São Paulo: Brasiliense, 1987, p. 223.

4 É por isso que termos ou conjunto de termos tāo carregados histórica e intelectualmente como "história", "humanidade redimida", "verdade", "juízo final" são utilizados por Benjamin, ao longo de grande parte de sua obra e especialmente nas "Teses", com uma tal naturalidade: indicam seus próprios limites, despojam-se de sua carga de séculos e se dão simplesmente a uma inteligibilidade que penetra nas bases de um universo de sentido, expondo-se simultaneamente à degradação de uma tradição petrificada e univoca e frutificando de forma nova na estrutura temporal da leitura, da mente do leitor: uma espécie de recriação radical de sentido.
} 
história não julga, mas é julgada pela citação do momento e pela narração dos fatos que, relegados a sombras, vivem em sua realidade de inscrição definitiva porque real - na ordem dos acontecimentos ${ }^{5}$.

E tal citação não se dá por acaso, pelo espírito absoluto ou por uma ordem intemporal, mas por um cronista que leva o tempo a sério. $\mathrm{E}$, ao levar o tempo a sério, o cronista leva a sério a diferença entre o que é narrado e a narração que simultaneamente revigora o narrado e abre um espaço de imponderabilidade onde, de alguma forma, é concebível que o humano possa ter vez. Trata-se, em última análise, de repor em marcha a ordem da temporalidade; e o "juízo final" finaliza essa estranha reposição, configurando-se, por sua paradoxal "frutificação escatológica", em "juizo inicial" de uma era ética, onde o pequeno, os restos e sobras, o dispensável e o inofensivo têm sua dignidade maximamente respeitada pela "citação" inconfundivel de sua própria realidade também inconfundivel: sua diferença.

\section{Sentido de alteridade}

É evidente, em vista do referido, a possibilidade de conceber a intenção narrativa no sentido benjaminiano como conjunto de incisivas "sugestões de alteridade" no sentido em que, numa primeira e não falsa leitura - a primeira de muitas possiveis à medida em que se mergulha na estrutura de sua obra em sua espantosa riqueza - se compreende o termo "alteridade" tal como é normalmente utilizado por Levinas. O que está em jogo, a sugestão elementar que aqui nos interessa, é que por sob a estruturação de um discurso está toda a inconfundível pulsação de um tempo, ou seja, estão as questões centrais de uma época; e que isso raramente se dá de forma tão aguda como nas estranhas e aparentemente paradoxais interfaces que o ritmo histórico do século XX nos proporcionou. Para além da formalização consubstanciada numa determinada filosofia num determinado momento histórico, necessário se faz ler os impulsos que a determinaram, perceber a "atmosfera" de um amplo contexto de referências ${ }^{6}$. É na aproximação das questões centrais que essa atmosfera evidencia que uma filosofia conseqüente pode ser concebida.

Tal situação de fidelidade às questões de origem - em Levinas, à questão do perguntar pelo sentido que pode assumir a pergunta pelo sentido do ser e da realidade - nos conduz necessariamente a uma situação de fronteiras e de precariedade discursiva; tal não é um defeito, mas uma certamente grande virtude. Nos desvãos da articulação bem-acabada de uma determinada inteligibilidade, lateja a virtualidade da pluralidade, da constante redescoberta da questão dos sentidos do novo em proposições de inteligibilidade que constantemente se propõem e repro-

5 Faz-se necessário que se tenha muito presente a inspiração de Rosenzweig no que diz respeito à questão da temporalidade em W: Benjamin. Sobre a temporalidade em Rosenzweig, cf. nosso livro Existência em decisão - uma introdução ao pensamento de Franz Rosenzweig (São Paulo: Perspectiva, 1999), especialmente p. 124-139.

6 Cf. ROMBACH, Heinrich. Phänomenologie des gegenwärtigen Bewusstseins. Freiburg: Alber, 1980, p. 7 ss. 
põem, e não permanecem em si. Em Levinas como em Benjamin, como em inúmeros outros pensadores lúcidos desse difícil século que ora finda, a questão do sentido é antes a questão da construção ética do sentido; e é nessa direção que cada momento da vida se constitui num inadiável instante de decisão que sustenta a possibilidade da crença num futuro humanamente possivel. 